\title{
LA (RE)CONSTRUCCIÓN DE LA MEDINA MARROQUÍ EN LAS NOVELAS DE JUAN GOYTISOLO REIVINDICACIÓN DEL CONDE JULIÁN Y MAKBARA
}

\author{
Renata Haffaf
}

\begin{abstract}
The Islamic city emerges in the modern Spanish prose as a dreamworld or space frozen in time a result of its idiosyncratic characteristics as well as aesthetic, cultural and ideological factors. While Juan Goytisolo explores the Moroccan cities of Tangier and Marrakech in his novels Count Julian (1970) and Makbara (1980), such a traditional representation is consciously integrated into the narration. At the same time the medina is textually reconstructed, some of its elements become central to the writing, linking its "antiquated" space with the author's understanding of modernity.
\end{abstract}

Keywords: Morocco in literature; oral literature; urban space; Islamic city; labyrinth; Orientalism.

Resumen: La ciudad islámica surge de la prosa española como un mundo ensoñado o adormido en el tiempo, resultado tanto de sus características peculiares como de los factores estéticos, culturales e ideológicos. Cuando Juan Goytisolo explora las ciudades marroquíes de Tánger y Marrakech en sus novelas Reivindicación del Conde Julián (1970) y Makbara (1980), integra la representación tradicional en su narración. Al mismo tiempo que el autor reconstruye la medina a través el texto, reafirma su vitalidad conceptual al convertir algunas de sus propiedades en la espina dorsal de su narración. El espacio «anticuado» de la medina queda así vinculado con la modernidad, tal como la entiende el propio autor.

Palabras clave: Marruecos en la literatura; literatura oral; espacio urbano; ciudad islámica; laberinto; Orientalismo.

\section{Introducción}

Debido tanto a sus características particulares, como a un conjunto de motivos estéticos, culturales e ideológicos, la ciudad islámica se perfila en la literatura española como un espacio atemporal, ajeno al desarrollo de la sociedad occidental, incluso opuesto a él.

En el presente trabajo comentaremos la persistente visión de la ciudad islámica envuelta en su propio tiempo-espacio, sea ensoñado o adormido en el pasado, tal como surge de la prosa española del tema marroquí del último siglo y medio ${ }^{1}$, para confron-

\footnotetext{
1 Es junto con la Guerra de Marruecos (1859-1860) cuando, en la época moderna, empiezan a desarrollarse más intensamente las relaciones entre España y su vecino norteafricano. Junto con la política colonial y expansionista de España crece el interés por los estudios árabes y España se abre -con un retraso respecto a países como Francia o Inglaterra- a la fascinación del mundo occidental por el mundo oriental.
} 
tarla con la (re)construcción literaria de la medina llevada a cabo en las novelas de Juan Goytisolo, Reivindicación del Conde Julián² (1970) y Makbara (1980).

Según nuestras observaciones, dicha (re)construcción transcurre a tres niveles: a nivel de imágenes individuales que componen el «imaginario» tradicional de la medina; a nivel estructural, es decir, a nivel del espacio en su conjunto, entendido como patrón y aplicado a la estructura de la narración; y a nivel de la voz, enriquecida por el discurso polifónico y palimpséstico de Xemáa-el-Fná, el famoso zoco de Marrakech. Nos centraremos en los últimos dos niveles en los que, como proponemos, se invierte la visión tradicional de la medina.

Para este propósito, se tendrán en cuenta también las características urbanísticas de la medina y el desarrollo al que se enfrentan las ciudades marroquíes desde finales del siglo XIX.

\section{Los tiempos de la medina}

Independientemente de los valores que al final se le adjuntan, la medina está teñida de un aire onírico o «cuelga» en un tiempo pasado, en una época por la que Europa pasó hace siglos.

Es un espacio apropiado para escapar de la sociedad mecanizada e industrializada y para experimentar sensaciones fuertes. La descripción de la medina y la de su ambiente preindustrial obedece a ciertos códigos estéticos. Se resaltan imágenes pintorescas y exóticas y se evoca la impresión de volver en el tiempo, de trasladarse a la antigüedad. Así, la ciudad de Fez sigue siendo a finales del siglo XX «una ciudad dormida en el pasado y despertada de pronto, para ellos, turistas vulgares, con todo el hechizo del Islam» (Alperi 1982: 62), o se desvela como «tiempo convertido en polvo, adherido a su caminar; escenas bíblicas usurpadas a las antiguas escrituras» (López Sarasúa 1988: 46).

A partir del placer estético que la sensación del «viaje al pasado» produce, muchos autores se fijan en el «retraso» urbanístico de la medina. El tono negativo reina sobre todo en textos apologéticos de las primeras décadas del siglo $\mathrm{XX}$, cuyo objetivo principal fue demostrar el subdesarrollo de la sociedad marroquí y justificar la acción militar española y la necesidad de la misión civilizadora.

La literatura española cuenta también con un factor específico, debido a los lazos históricos y culturales entre los dos países del Estrecho y a la compleja mirada hispánica hacia el «moro» como resultado de éstos. Las similitudes identificadas suelen relacionarse directamente con épocas históricas concretas, como el período del Al-Andalus y la Edad Media, lo que refuerza la sensación de volver en el tiempo. Eso ocurre tanto con los aspectos visuales y urbanísticos de la medina como con sus habitantes ${ }^{3}$.

\section{Los espacios de la medina}

Desde el punto de vista urbanístico, tal y como señala Chueca Goitia (1982: 83-103), la medina se divide tajantemente en la zona pública y en la zona privada. La literatura ha claramente reflejado esta diferencia fundamental, ya que cada una de estas zonas confiere al autor/observador roles y posibilidades distintos.

\footnotetext{
2 Más adelante en el texto abreviado como $R D C J$.

3 Arturo Barea (1986: 90) dice por ejemplo sobre Xefchauen: «en medio de tal mezcla de razas [...] en tal mezcla de religiones rivales [...] era para mí como si la España medieval hubiera resucitado y estuviera ante mis ojos».
} 
En la zona pública se encuentran las calles comerciales, mercados, baños públicos y mezquitas. Es este medio urbano a donde acude la población para satisfacer todo tipo de necesidades. Aquí reina el caos, ruido, colores y olores. Aquí se instalan los artesanos como en un museo de labor preindustrial, aquí desfilan los saltimbanquis, cuentistas, mendigos y personajes estrafalarios, que parecen haber salido directamente de la Edad Media. Como en el teatro, el escritor se convierte en espectador. Por ejemplo, a Giménez Caballero (1983: 100) el zoco de Tetuán le parece un espectáculo diario, «una pura fantasía [...], un gran trozo de un ballet ruso de una leyenda que iluminase un momento, como una bengala, la vida real y descolorida. [...] es como haber tomado una localidad en un ensueño hermoso».

En las zonas residenciales, el escenario cambia. Allí, las calles fueron concebidas para pasar y no para demorarse en ellas y su diseño respondía a varias funciones que en su conjunto fomentaban el pronunciado carácter laberíntico. Señalamos, entre otras, su función defensiva ${ }^{4}$ o la de proteger del sol y de la deslumbrante luminosidad.

Las calles estrechas e irregulares de la medina, con sus culs-de-sac, rincones y ángulos inesperados, y formadas por casas de aspecto homogéneo crean un verdadero laberinto, provocando la sensación en el transeúnte de haber penetrado en terrenos privados. En la literatura, esta parte de la medina se presenta por lo tanto como un espacio poco penetrado y misterioso. También aquí reina un caos, pero es un caos producido por el diseño «sin plan» y difícil de «leer» por el escritor-intruso.

\section{El laberinto versus la línea recta}

La medina sigue en su propio tiempo-espacio a pesar de que ya a partir de finales del siglo XIX las ciudades marroquíes empiezan a notar cambios significativos por la influencia occidental. De hecho, la urbe marroquí queda dividida en dos partes, cada vez más separadas una de la otra. La medina marroquí, envuelta en sus propios valores y en su tejido social tradicional, sigue representando el mundo ensoñado, adormido, medieval y oriental. Su laberinto se encuentra rodeado de la nueva ciudad que crece a su alrededor, de la nueva manera de pensar, influida por y diseñada ya con los códigos estéticos y funcionales occidentales.

La creciente escisión de la ciudad marroquí en dos mundos, el tradicional y el moderno, encuentra en la literatura española expresiones y representaciones muy distintas. Mientras que unos lamentan la muerte lenta de su propio sueño oriental, otros se alegran de los progresos civilizadores. El espíritu romántico se enfrenta al espíritu civilizador, y los dos se juntan en la particular visión orientalista, desafiada por Edward Said, que peca tanto de estereotipo como de paternalismo. Por otra parte, el crecimiento de los barrios nuevos frente a la medina lleva a los autores a «tomar partido» de uno de los dos mundos o plantearse preguntas acerca de los valores que cada uno representa.

Junto con el desarrollo urbanístico, la medina islámica deviene en un espacio limitado dentro de la ciudad. De hecho, como pasa por ejemplo en muchos textos relativos a Tánger, la medina recogida en su propio tiempo-espacio se hace casi invisible, como si su existencia no fuera compatible con la actualidad. En la visión nostálgica de Antonio Ortiz Muñoz de 1951, las estrechas calles tangerinas ya han desaparecido por completo

\footnotetext{
4 Juan Goytisolo habla de la función defensiva en uno de sus ensayos, señalando cómo el laberinto de la medina desorienta a los intrusos y como «un puñado de hombres a la entrada de calleja podía impedir el paso a un ejército» (Goytisolo 1997: 29).
} 
y, para enfatizar su proclamada ausencia, Ortiz Muñoz las recuerda citando a otro autor, como si él mismo ya no pudiera verlas con sus propios ojos: «Ya no hay aquel claroscuro de calles estrechas, <donde las azoteas se acercaban y juntaban como si quisiesen contarse un secreto'. [...] Hoy, las calles son abiertas, y se llaman bulevares, y alinean rascacielos imponentes» (Ortiz Muñoz 1989: 146).

La independencia de Marruecos en 1956 invierte los antiguos roles coloniales. La población autóctona se libera de repente de su posición tradicional y el placer de observar las escenas pintorescas cede ante el proceso doloroso que tal cambio supone para muchos españoles. La literatura tardará en «digerir» esta nueva situación. La supresión o desaparición temporal de las imágenes de la medina del ensueño, de la medina «kodesca» y «fotografiable» ${ }^{5}$, será uno de los efectos de la reconciliación con la realidad. Como ejemplo pueden, tal vez, servir las dos grandes novelas del tangerino Ángel Vázquez, Se enciende y se apaga una luz (1962) y La vida perra de Juanita Narboni (1976). En ellas, la ciudad islámica y sus habitantes están literalmente «eliminados» del campo visual y sólo se intuyen como elementos que progresivamente amenazan la vida establecida de los protagonistas.

Cuando en 1970 Juan Goytisolo publica su novela RDCJ, entra en este columpio de valores, transmitidos a través de la presencia/ausencia y exaltación/degradación de la medina marroquí, con sus propios fines creativos. Al proponerse en Tánger la desmitificación de la España tradicional y la revalorización del elemento islámico y árabe en España, busca la medina tangerina y la «reedifica» en la literatura española.

Se aventura «hacia dentro, hacia dentro: en la atmósfera algodonosa y quieta, por los recovecos del urbano laberinto, como en la galería de espejos de una feria, sin encontrar la salida» (Goytisolo 1999: 78) y, como otros antes de él, opone la estructura espontánea y laberíntica de la ciudad islámica al racionalismo y planificación de las partes modernas:

[...] la calle del Horno: estrecha y cubierta, con las fachadas casi juntas: asimetría concertada de alarife ocurrente, aprovechado, tenaz: superficies y planos que escapan a Descartes y también a Haussmann: líneas y segmentos hacinados como para alguna proposición geométrica indemostrable (Goytisolo 1999: 46).

Frente a la planificación de las avenidas anchas escoge la espontaneidad y adaptabilidad del laberinto y refleja su selección en su propia escritura. Mientras que evita los bulevares, camina por la medina calle por calle. Recrea su estructura espontánea a través del vuelo caótico de las imágenes que escribe y reescribe como sus propios pasos. Crea imágenes cruzadas, laberinto de motivos que se quedan colgados en medio de la narración como en recovecos sin salida para reaparecer después en otro contexto, en otra calle claroscura...

[...] perdiéndote en dédalo de callejas de la Medina: trazando con tus pasos (sin previsores guijarros ni migajas caducas) un enrevesado dibujo que nadie (ni tú mismo) podrá interpretar... consciente de que el laberinto está en ti: que tú eres el laberinto (Goytisolo 1999: 48).

Goytisolo crea un texto-medina, como lo llama Alberto Ruiz Campos ${ }^{6}$, aplicando las características, funciones y valores de la antigua ciudad islámica a la narrativa. El lector tiene que tener el valor de adentrarse en el texto, aunque no exista ningún plan que le guíe a través de la red enrevesada de la narración. Es más, el lector es un intruso en el terreno privado. Como a cualquier desconocido que se proponga conquistar la antigua

\footnotetext{
Adjetivos usados por Caballero (1983: 92) para caracterizar el zoco de Tetuán.

6 Alberto M. Ruiz Campos (1996: 95) habla del texto-medina en relación con la estructura narrativa de Makbara.
} 
kasbah hay que demorarlo, obstruirle el paso, poner obstáculos, desviarlo, sin que nunca pueda conquistar el texto por completo.

\section{El sueño de la voz y la modernidad del medievalismo}

Desde el punto de vista de nuestra lectura, hay una diferencia sustancial en el enfoque y función de la medina en las dos novelas. En RDCJ, éstos se proyectan sobre todo a partir de las características y valores asociados con el tejido callejero (laberíntico, encerrado, desorientador, inaccesible). En Makbara, por otro lado, la representación y función de la medina giran alrededor de la zona pública, en particular, alrededor de la abierta y siempre cambiante plaza de Xemáa-el-Fná.

A lo largo de la novela, la plaza se manifiesta más bien a través de imágenes aisladas y esparcidas, pero en el último capítulo titulado «Lectura del espacio de Xemáa-el-Fná» recobra un protagonismo inesperado, revelándose como la clave de la lectura del texto en su totalidad. Además, la plaza se erige como un espacio idealizado. Es un espacio donde soñar, un espacio del «olvido de las coacciones sociales, identificación en la plegaria y risa, suspensión temporal de jerarquías, gozosa igualdad de los cuerpos» (Goytisolo 1999: 288).

Su descripción se caracteriza por una enumeración extensa de varias páginas, recurso tan aprovechado tradicionalmente para describir el ambiente recargado, exótico y caótico del zoco. En la imagen creada por Goytisolo (1999: 288), la vitalidad e hibridez del ambiente lo absorbe todo, «campesinos, pastores, áscaris, comerciantes, chalanes venidos de las centrales de autocares, estaciones de taxis». El cliché, la imagen, la narración y la realidad se hacen inseparables, impregnándose uno en el otro: «aprehensión del universo a través de las imágenes de Sherezada o Aladino: la plaza entera abreviada en un libro, cuya lectura suplanta la realidad» (Goytisolo 1999: 312).

Tan significativa como la exaltación de la plaza en sí es la exaltación de la figura del halaiquí, el cuentista tradicional, y de su arte verbal. El autor ha confesado en varias ocasiones cómo las escenas presenciadas en la plaza de Xemáa-el-Fná le han permitido volver en el tiempo y poder contextualizar y sobre todo «oír» el inclasificable y profundamente mudéjar Libro de Buen Amor de Arcipreste de Hita. Junto con la modernidad identificada en el texto medieval de Juan Ruiz y caracterizada por Goytisolo (1985: 14) como «apertura, insumisión a las reglas establecidas, mescolanza de estilos al servicio de una unidad estética superior o reflexión del autor sobre la propia escritura y configuración del texto», el autor actualiza también el espacio medieval de la plaza en la que distingue las mismas calidades.

El ambiente del zoco le posibilita una nueva «puesta en escena» de aquel singular libro medieval, de los valores mudéjares y de la oralidad ${ }^{7}$. Irónicamente, por la apertura a posibilidades infinitas de su «discurso» tanto visual como verbal, la plaza se erige como el símbolo puro de la modernidad literaria, tal como la entiende el propio autor.

La hibridez y «liberación del discurso, de todos los discursos opuestos a la normalidad dominante: abolición del silencio implacable infligido por las leyes, supersticiones, costumbres: en abrupta ruptura con dogmas y preceptos oficiales: [...] habla suelta, arrancada de la boca con violencia» (Goytisolo 1999: 310). La constante «de(con)strucción perpetua» tanto del espacio de la plaza como de la narración oral, «lienzo de Penélope

\footnotetext{
7 Sobre el último aspecto, véase por ejemplo el estudio de Gómez Mata y Silió Cervera (1994: 12-64).
} 
tejido, destejido día y noche» (Goytisolo 1999: 309), se unen con la escritura laberíntica iniciada en $R D C J$, dando paso al ideal de «lectura en palimpsesto: caligrafía que diariamente se borra y retraza en el decurso de los años: precaria combinación de signos de mensaje incierto: infinitas posibilidades de juego a partir del espacio vacío» (Goytisolo 1999: 313).

La plaza de Xemáa-el-Fná le permite a Goytisolo inspirarse en la narración oral tradicional y, al mismo tiempo, infinitivamente renovadora de los halaiquís. Allí puede revivir el ambiente cultural de la España medieval con su mester de juglaría. Allí también presencia cómo lo tradicional pasa con una fluidez natural a lo que podría tacharse de «vanguardista» en el ambiente cultural europeo y allí observa a los «chiflados» de la hal$c a$, dotados de una lucidez verbal impresionante y despojados de cualquier pudor, parecidos en este aspecto al singular y rebelde amigo del autor, el escritor francés Jean Genet.

La medina de Makbara, representada por Xemáa-el-Fná, mantiene sus características de espacio ensoñado. No obstante, su idealización no radica en el exotismo del ambiente ni en el sueño oriental tradicional, sino en la libertad y riqueza de la expresión oral, en la posibilidad de la recuperación de la voz. Allí, en la plaza de Xemáa-el-Fná, el más marginado puede «perder la afonía: [...] dirigirte al público de la halca: hablar y hablar a borbollones durante horas y horas: vomitar sueños, palabras, historias hasta quedarte vacío» (Goytisolo 1999: 317).

\section{Conclusiones}

La compleja representación de la medina en las novelas Reivindicación del conde Julián y Makbara está erigida a partir del imaginario y conceptos arraigados en la tradición anterior, en la que se perfila como un espacio onírico o del pasado, aislado de la actualidad occidental.

A nivel estructural, la narración goytisoliana se nutre de los valores que el autor reconoce en la estructura laberíntica de la medina. Las novelas comentadas se incorporan así en el diálogo intertextual en el cual se enfrentan el laberinto y la línea, es decir, en el cual el arcaísmo de la medina, caracterizado por su espontaneidad y valores tradicionales, se opone a la modernidad de la nueva urbe planificada y regularizada. Goytisolo opta por el laberinto y reafirma su vitalidad conceptual al convertirlo en la espina dorsal de su propia narración.

A nivel del discurso narrativo, la novela Makbara se enriquece con la voz del halaiquí, cuentista tradicional, y con el carácter polifónico y palimpséstico de la plaza de Xemáael-Fná. Como tantos escritores españoles antes de él, Goytisolo llega a reconocer en el ambiente presenciado momentos de la historia y cultura de su propio país. El ambiente «medieval» de la plaza y de sus protagonistas le posibilita el reencuentro con la España medieval y con el arte de Arcipreste de Hita. Pero en vez de ser un viaje al pasado, la experiencia narrativa de Goytisolo llega a convertirse en el camino hacia la modernidad.

\section{Bibliografía}

Alperi, Víctor (1982), Alá bendice Marruecos, Gijón: Ediciones Noega.

BAREA, Arturo (1986), La ruta, Barcelona: Plaza y Janés.

Chueca Goitia, Fernando (1982), «El Urbanismo Islámico», in: Vivienda y Urbanismo en España, Barcelona: Banco Hipotecario de España, 83-103.

Giménez CabAllero, Ernesto (1983), Notas marruecas de un soldado, Barcelona: Planeta. 
Gómez Mata, Marta - Silió Cervera, César (1994), Oralidad y Polifonía en la Obra de Juan Goytisolo, Madrid: Ensayos Jucar.

Goytisolo, Juan (1985), Contracorrientes, Barcelona: Montesinos.

Goytisolo, Juan (1997), De la Ceca a la Meca, Madrid: Alfaguara.

GoYTisolo, Juan (1999a), Makbara, Barcelona: Galaxia Gutenberg.

Gortisolo, Juan (1999b), Reivindicación del Conde Julián, Madrid: Alianza Editorial.

López Sarasúa, Concha (1988), A vuelo de pájaro sobre Marruecos, Alicante: Editorial Cálamo.

Morales Lezcano, Víctor (1993), España y mundo árabe, Imágenes cruzadas, Madrid: Agencia Española de Cooperación Internacional, Instituto de Cooperación con el Mundo Árabe.

Ortiz MuÑoz, Antonio (1989), «En la otra orilla del Estrecho», in: DjBILOU, Abdellah (ed.), Tánger, Puerta de África, Antología de textos literarios hispánicos 1860-1960, Madrid: Editorial CantArabia, 143-148.

Ruiz Campos, Alberto M. (1996), Estructuras literarias en la nueva narrativa de Juan Goytisolo, Almería: Instituto de Estudios Almerienses.

SAID, Edward W. (2002), Orientalismo, Madrid: Debate.

VÁzQUEZ, Ángel (1962), Se enciende y se apaga una luz, Barcelona: Editorial Planeta.

VÁzQueZ, Ángel (2000), La vida perra de Juanita Narboni, Madrid: Ediciones Cátedra.

Renata Haffaf

Ústav románských jazyků a literatur

Filozofická fakulta

Masarykova univerzita v Brně

Arna Nováka 1

60200 Brno

República Checa

haffaf@volny.cz 